\title{
Variations in antioxidant defense during the development of the solitary bee Osmia bicornis
}

\author{
Kamila DMochowsKa-ŚLęzaK ${ }^{1}$, Karol GIEJdAsz ${ }^{2}$, Monika FliszKIEwICZ², \\ Krystyna ŻóŁTOWSKA ${ }^{1}$ \\ ${ }^{1}$ Department of Biochemistry, Faculty of Biology and Biotechnology, University of Warmia and Mazury, \\ Oczapowskiego 1A, 10-719, Olsztyn, Poland \\ ${ }^{2}$ Department of Apidology, Institute of Zoology, Poznań University of Life Science, Wojska Polskiego 71C, 60-625, \\ Poznań, Poland
}

Received 4 April 2014 - Revised 23 September 2014 - Accepted 21 October 2014

\begin{abstract}
An efficient antioxidant system is of particular importance for insects whose high metabolic rates promote increased formation of reactive oxygen species (ROS). The amount of ROS can be additionally increased by environmental factors. This study investigates the ability of red mason bees (Osmia bicornis L.) to inactivate free radicals during insect development. Both male and female bees were studied, from the larval to the active imago stage. The activity of four antioxidant enzymes, superoxide dismutase, catalase, peroxidase and glutathione Stransferase, was measured; and glutathione content and total antioxidant status were determined. The highest values of the examined parameters were found in feeding stages-in larvae and in active imagines of both genders. Significant differences between genders were noted mainly in catalase activity, which was lower in overwintering imagines and active females than in males. Most differences were observed between females and males after emergence.
\end{abstract}

antioxidants / pollinating insects / insect metabolism / development / enzymes

\section{INTRODUCTION}

The populations of pollinating insects are declining globally, which leads not only to a huge natural deficiency, but also measurable economic losses (Klein et al. 2007; Potts et al. 2010). The problem is exacerbated by the sudden reduction in the honeybee (Apis mellifera L.) populations. This phenomenon, referred to as the colony collapse disorder (CCD) syndrome in North America and the colony depopulation syndrome (CDS) in Europe, has been researched extensively, but its causes remain largely unknown. It is believed that the syndrome results from coincident harmful

Corresponding author: K. Dmochowska-Ślęzak, kamila.dmochowska@uwm.edu.pl

Manuscript editor: Monique Gauthier factors, including the parasitic mite Varroa destructor (Dietemann et al. 2012).

The rapid decline in $A$. mellifera populations has prompted researchers to search for alternative solutions, including replacement pollinators such as solitary bees. One of them is the red mason bee (Osmia bicornis L.). Red mason bees and honeybees belong to the same superfamily of Apoidea . Similarly to A. mellifera, red mason bees have a haplodiploid genetic system, but they clearly differ in their social behavior and life cycle, which makes them a very interesting object of comparative research. As pollinators, O. bicornis also have many useful features for planters. Above all, this polylectic insect is capable of pollinating numerous plant species. Its pollinating efficiency has been demonstrated by numerous studies of apples, strawberries, sour cherries, pears, rapeseed, red clover and black currants (Wilkaniec 1991; Biliński and Teper 2004; Teper and Biliński 
2009). Red mason bees have been found to significantly improve yield and crop quality (Wilkaniec 1991; Wilkaniec et al. 2004). The emergence of adult individuals from cocoons in which they diapause can be artificially accelerated or delayed, which increases the number of plant species that can be visited by bees to include taxa that blossom outside the bees' natural period of activity (April-June) (Wilkaniec 1991). O. bicornis also easily adapt to nesting in larger clusters, and they can be reared directly in plantations (Giejdasz and Wilkaniec 2000). O. bicornis is a univoltine and early spring species whose active season begins in the first half of April and ends in late June in north-central Europe. Males emerge first, whereas females leave their cocoons somewhat later, mate with males and search for a nesting place (Wilkaniec 1991). Nests comprise several to around a dozen cells separated by mud partitions. Females deposit pollen in each cell, where they lay an egg and plug it up (Wilkaniec 1991). Larvae hatch after one week, and they feed on the deposited pollen. One month later, larvae spin cocoons, inside which they undergo subsequent transformations into pre-pupae, pupae and adult insects (imagines) (Giejdasz and Wilkaniec 2002). Imagines appear in the cocoon at the end of summer and remain there until the following spring, when adult individuals emerge (Radmacher and Strohm 2011).

Similarly to all aerobes, red mason bees continuously produce reactive oxygen species (ROS). Free radicals are also generated in response to biotic and abiotic factors, including pathogens, UV radiation, ultrasound waves, and toxic substances in the environment and the diet (Bartosz 2003; Lipiński and Żółtowska 2005). The increased use of agricultural chemicals and growing environmental pollution pose the greatest threats to the survival of bees. Pesticide use is growing at an alarming rate globally (Tilman et al. 2001). Although bees are not the direct target of pesticides, they are often affected by indirect, negative effects of pesticide application (Henry et al. 2012; Whitehorn et al. 2012). Frazier et al. (2008) found as many as 17 various pesticides in one sample of pollen originating from an A. mellifera hive. Pollen is the main source of protein for bees (Herbert and Shimanuki 1978). Herbicides and insecticides provoke an increase in ROS production in insects (Hayaoka and Dauterman 1982; Després et al. 2007). ROS are very dangerous for living organisms because they oxidize fats, and damage protein and DNA. The generation of ROS in amounts that exceed the body's radical scavenging ability causes oxidative stress. Therefore, all aerobic organisms are equipped with a system that reduces the amount of ROS. The efficiency of the antioxidant system in bees is a vital consideration in view of the global threat to the survival of functional insects. A functional antioxidant system requires the cooperation of many specialized systems and particles. Those systems are made up of enzymes and non-enzymatic low-molecularweight antioxidants. In insects, the most important antioxidant enzymes are superoxide dismutase (SOD), peroxidase (POX), catalase (CAT) and glutathione S-transferase (GST). SOD plays an important role in enzymatic defense against harmful ROS generated by aerobic metabolism. SOD dismutates superoxide anions directly into molecular oxygen and potentially toxic hydrogen peroxide (Colinet et al. 2011). CAT converts hydrogen peroxide to water and oxygen. POX breaks down hydrogen peroxide into oxygen and water (Bartosz 2003). Insects have lost the genes coding two important antioxidative enzymes: glutathione peroxidase and reductase. In insects, glutathione S-transferase (GST) also plays the role of peroxidase and the main detoxification enzyme (Chien et al. 1995; Yu 1996; Corona and Robinson 2006). The most important non-enzymatic components are glutathione, ascorbic acid, vitamin E, uric acid and thioredoxin. Low-molecular-weight oxidants react with ROS less specifically than enzymes, and are therefore more universal, and may even assume their functions (Colven and Pinnell 1996).

During physiological processes and under pathological conditions, the amount of ROS dynamically changes and has to be constantly controlled. An efficient antioxidant system is of particular importance for insects whose high metabolic rate contributes to the production of large amounts of free radicals under physiological conditions (Candy et al. 1997). Bees of the genus Osmia are constantly exposed to potentially harmful pathogens and chemical compounds, not only through polluted food that is consumed by 
larvae and active bees, but also through nesting materials (Alston et al. 2007). The above observations have prompted us to investigate red mason bees' ability to inactivate free radicals and xenobiotics not only during the active season, but also in different stages of insect development in nests. Those abilities were evaluated based on the following parameters: total antioxidant status, glutathione content, activity levels of superoxide dismutase, catalase, peroxidase and glutathione Stransferase in the life cycle of $O$. bicornis .

\section{MATERIALS AND METHODS}

The research material comprised red mason bees (O. bicornis) of both genders. The bees were reared in artificial nest made of reed stalks (Wójtowski and Wilkaniec 1978). Samples were collected from June 2011 to May 2012. The following developmental forms were examined: the fifth larval stage (L), pre-pupae (PP), younger pupae (light body, LB), older pupae (dark body, DB) and adult insects. The following imagine forms were differentiated: 1) overwintering adults, which were examined at the beginning of each month between October and April, where an additional group was collected in mid-March (X-IIIm); 2) adults immediately after emerging from cocoons (mid-April; IV E); 3 ) active adults, caught with an entomological net near artificial nests at the beginning of May (V). The bees were weighed, placed in Eppendorf tubes and euthanized with liquid nitrogen. The material was stored at $-71{ }^{\circ} \mathrm{C}$ for further analysis.

Every month, 40 females and 40 males were randomly selected from the population of red mason bees. Bee extracts were obtained from individual females and males and prepared according to a previously described procedure (Dmochowska et al. 2012). Insects were homogenized individually in an ice bath for $1 \mathrm{~min}$ with $0.9 \% \mathrm{NaCl}$ at the $1: 10(\mathrm{w} / \mathrm{v})$ ratio. The homogenate of whole bee's body was centrifuged at $4{ }^{\circ} \mathrm{C}$ for $15 \mathrm{~min}$ at $15,000 \times \mathrm{g}$. The supernatant from below the fatty layer was carefully collected for further analyses. Total antioxidant status (TAS), glutathione levels (GSH), and total activity (mitochondrial, cytosolic and extracellular) of superoxide dismutase (SOD), non-specific peroxidase (POX), catalase (CAT) and glutathione Stransferase (GST), as well as protein content, were assayed in bee extracts.
Total antioxidant activity was assayed according to Re et al. (1999). The result was converted to singleelectron equivalents of Trolox/100 mg of tissue.

GSH was measured according to the method proposed by Ellman (1959), which involved nonenzymatic reduction of 5,5'-dithiobis(2-nitrobenzoic acid) (DTNB) by GSH. The bee extract was deproteinized with $10 \%$ TCA at the 1:12 ratio before analysis. Glutathione content was calculated from the standard curve drawn for $1 \mathrm{mM}$ of glutathione solution.

SOD activity was assayed using an SOD assay kit (Sigma-Aldrich, Switzerland), according to the manufacturer's instructions. This method employs xanthine oxidase to generate superoxide radicals from xanthine and oxygen, which reduce tetrazolium salt, WST-1(2(4-iodophenyl)-3-(4-nitrophenyl)-5-(2,4-disulfofenyl)$2 \mathrm{H}$-tetrazolium, monosodium salt) to form a yellow formazan dye. Samples were diluted tenfold with the dilution buffer included in the kit. Standard inhibition curves were generated using a standard bovine SOD of known activity (Sigma-Aldrich). SOD activity was expressed in international units (U) per mg of protein.

Non-specific POX (EC 1.11.1.7) activity was determined according to Chance and Maehly (1955). Enzyme activity was calculated based on the millimolar absorption coefficient of $2.47 \mathrm{mM}^{-1} \times \mathrm{cm}^{-1}$. IU activity was calculated per $1 \mathrm{mg}$ of protein.

CAT activity was measured based on reduction of absorbance resulting from enzyme-induced degradation of hydrogen peroxide during an exposure time of $15 \mathrm{~s}$ (Aebi 1984). The results were converted into millikatals (mKat) per mg protein.

GST activity was determined using the Rice-Evans method (1991). Enzyme activity was calculated on a basis of the millimolar absorption coefficient $\left(9.6 \mathrm{mmol}^{-1} \mathrm{~cm}^{-1}\right)$ for glutathione conjugate formed from 1-Chloro-2,4-dinitrobenzene. Enzyme activity was converted into the number of units (U) per $1 \mathrm{mg}$ of protein.

The proteins were assayed spectrophotometrically at a wavelength of $280 \mathrm{~nm}$ (Aitken and Learmonth 1996).

The results were subjected to statistical analysis using Statistica 8 software (StatSoft Inc., Tulsa, Oklahoma, USA). Two-way ANOVA was used to measure the effect of developmental stage and sex and the interaction of those variables on the analyzed parameters. An ANOVA with a $p$ value $\leq 0.05$ was considered significant. A Tukey's test was used for post-hoc analysis of the significant ANOVA. 


\section{RESULTS}

Changes in the values of all analyzed parameters were observed during the development of O. bicornis (Figs. 1, 2, 3, 4, 5, and 6). The highest parameter values were generally noted in feeding stages, i.e., in larvae and in active individuals sampled in May. The only exceptions were TAS and GSH (Figs. 1 and 2). In overwintering imagines, the remaining parameters were stable and lower than at the beginning and end of the experiment. TAS values remained at a relatively high and stable level, after which they decreased significantly (Fig. 1). The lowest TAS values were
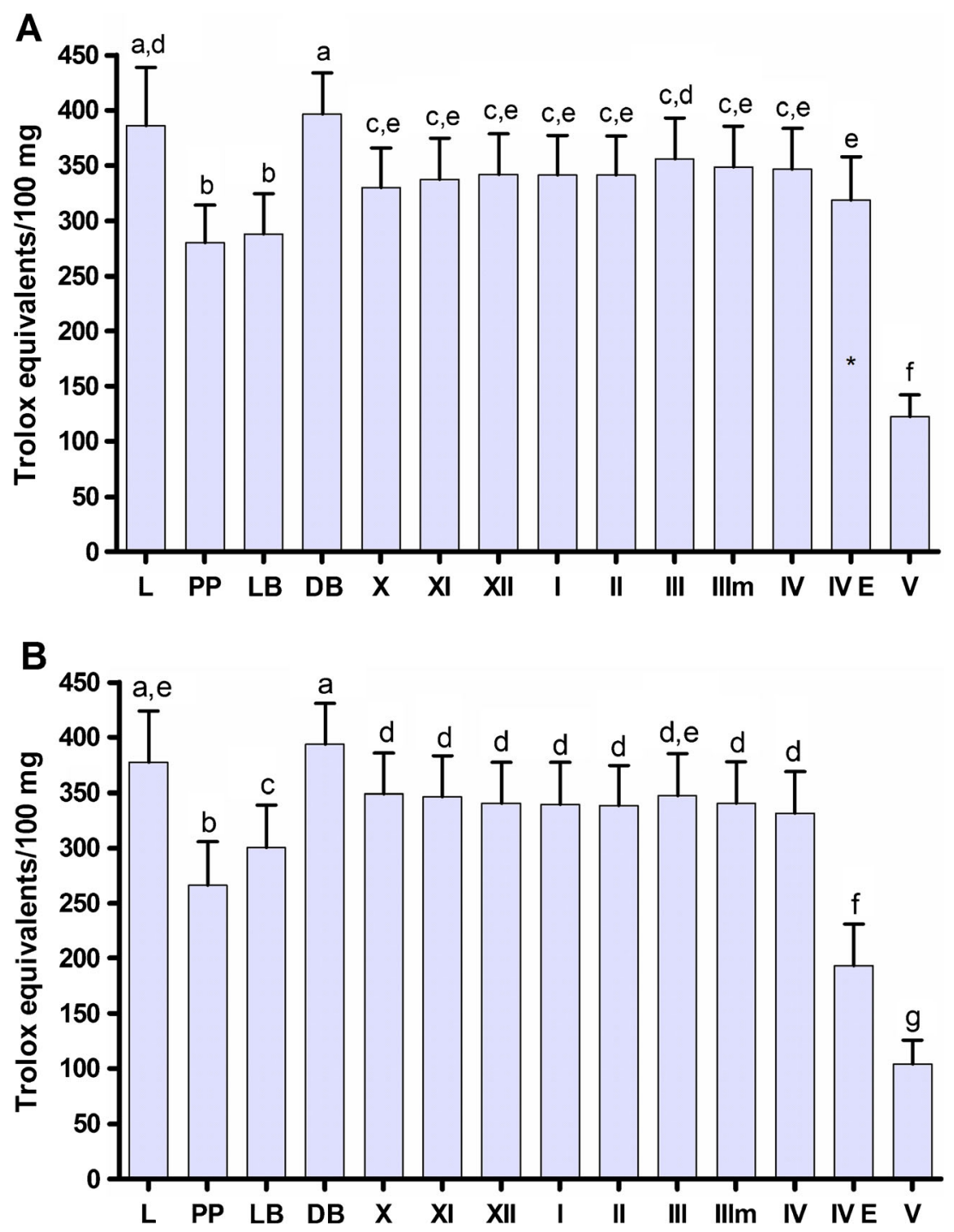

Figure 1. Total antioxidant status of Osmia bicornis female (A) and male (B). L - the fifth larval stage, PP - prepupa, LB - younger pupa (light body), DB - older pupa (dark body), X-IV - overwintering adults between October and April examined at the beginning of month, IIIm - overwintering adults examined in the middle of March, IV E freshly emerged imago, V - active adults. Data were expressed as means \pm SD. Different letters at the top of bars represent significant differences $(p<0.05)$ between means of stages. Asterisks entered in bars indicate significant differences $(p<0.05)$ between the sexes in the given stage. 

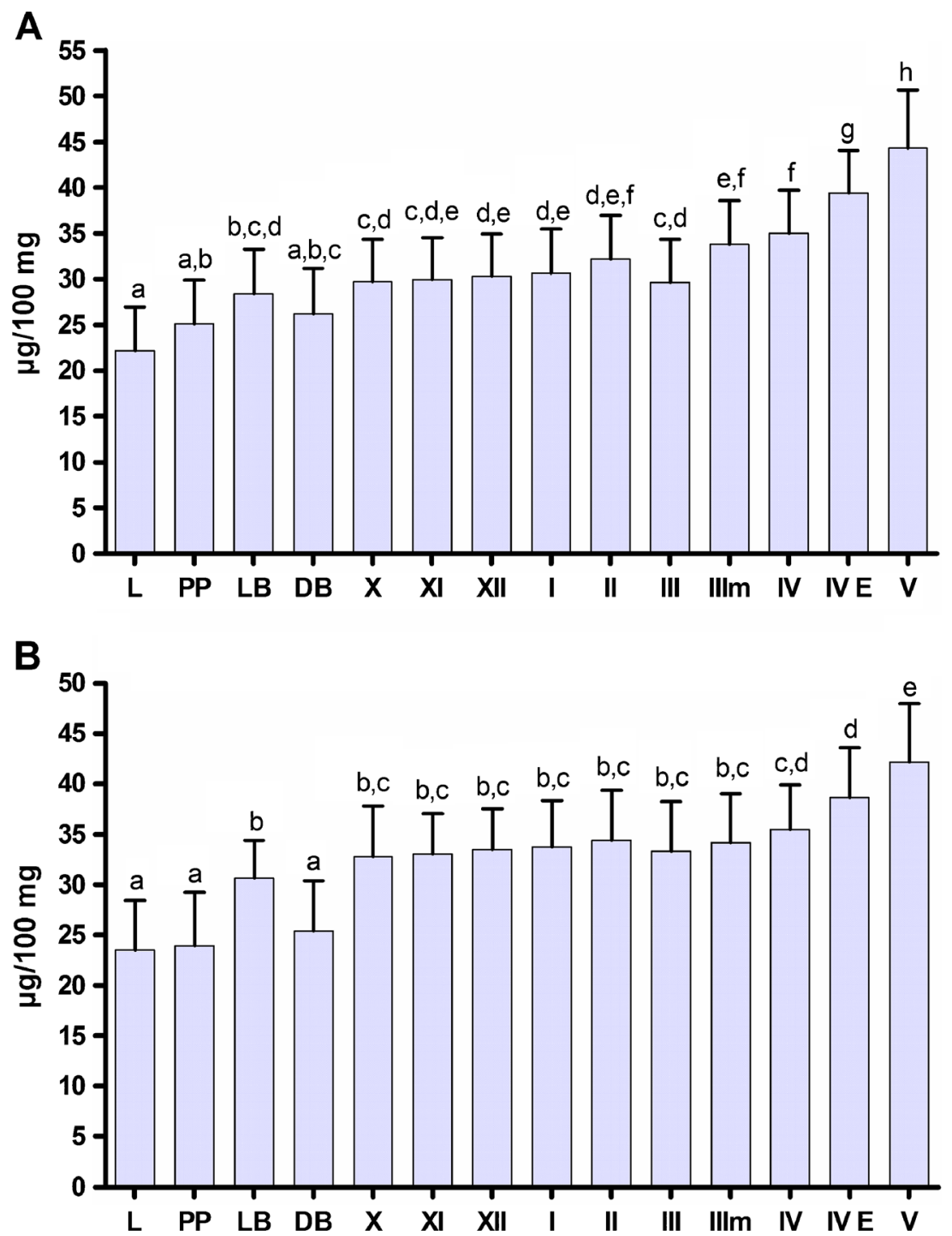

Figure 2. Glutathione level of Osmia bicornis female (A) and male (B). For explanation, see Fig. 1.

found in active specimens. Statistically significant differences in TAS values between males and females were observed only in a group of newly emerged adults.

A moderate, but statistically significant, increase in GSH values was noted in developing females. In both sexes, the lowest GSH values were reported in larvae and pre-pupae, and the highest were reported in active adults. No differences in GSH levels were observed between genders in corresponding age groups (Fig. 2).
SOD activity was lower in pupae than in larvae, and it remained at a similar level until imagines emerged from cocoons (Fig. 3). The highest levels of SOD activity were noted in active insects. Statistically significant differences between the sexes were found only in newly emerged individuals. SOD activity was twice as high in males than in females.

The pattern of changes in POX activity was similar to that described in SOD (Fig. 5 vs. 3). Although POX activity was higher in females than in males in all examined stages, statistically 

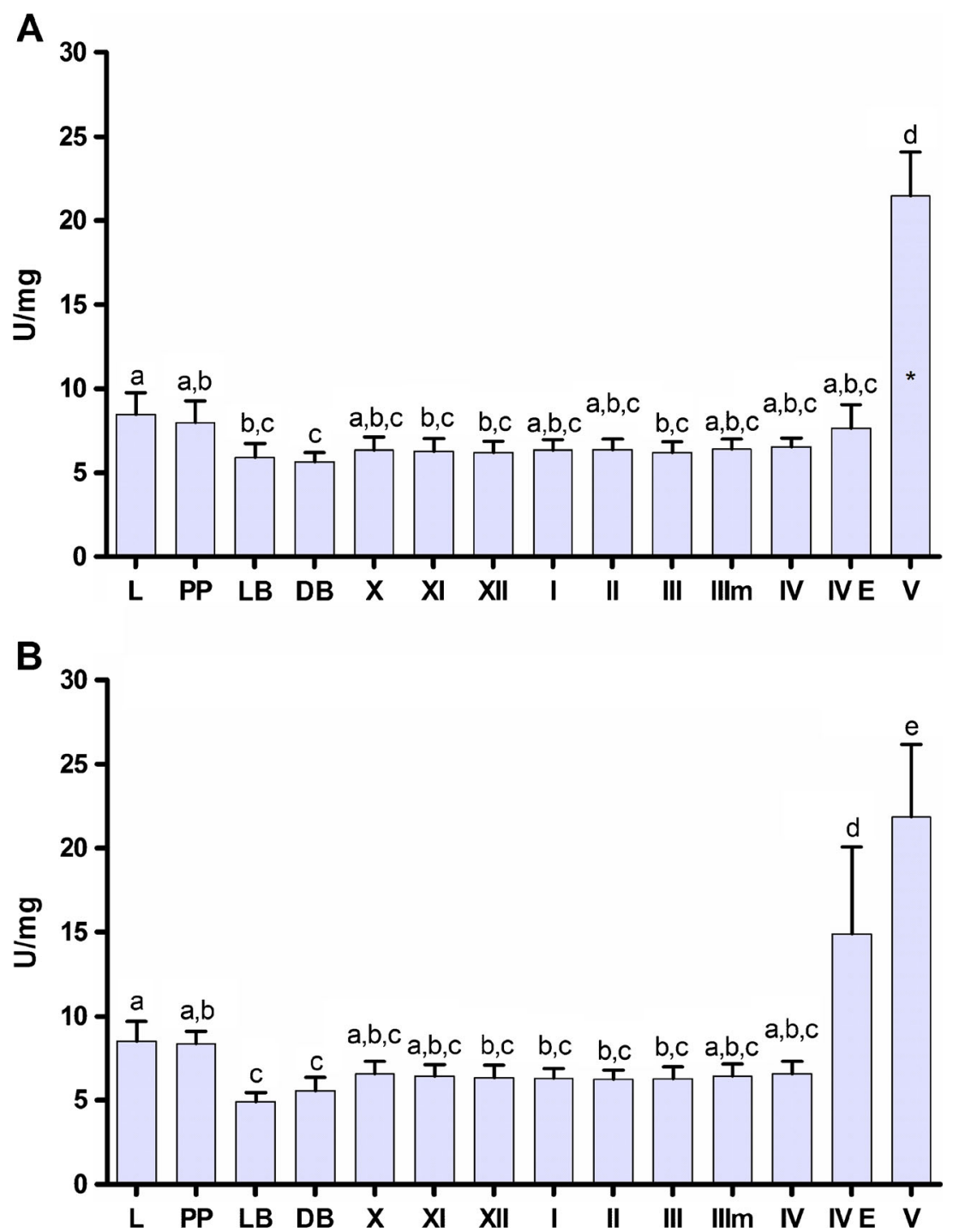

Figure 3. The activity of superoxide dismutase of Osmia bicornis female (A) and male (B). For explanation, see Fig. 1.

significant differences were reported only in active individuals. Significant sex-related differences were noted in catalase activity after metamorphosis in imagines (Fig. 4). In females, CAT and GST activity levels were higher in larvae than in flying insects (Figs. 4 and 6). The reverse was observed in males where enzyme activity levels were higher in active individuals than in larvae. In comparison with males, the pre-pupae of females were characterized by significantly higher levels of GST activity, whereas newly emerged and active individuals were characterized by significantly lower levels of GST activity (Fig. 6).

\section{DISCUSSION}

An efficient antioxidant system promotes free radical scavenging activity and repairs the damage done to biomolecules that are essential for life. The efficiency of the antioxidant system is also important in insects, at each stage of their ontogenesis. In larvae, antioxidant levels are crucial 

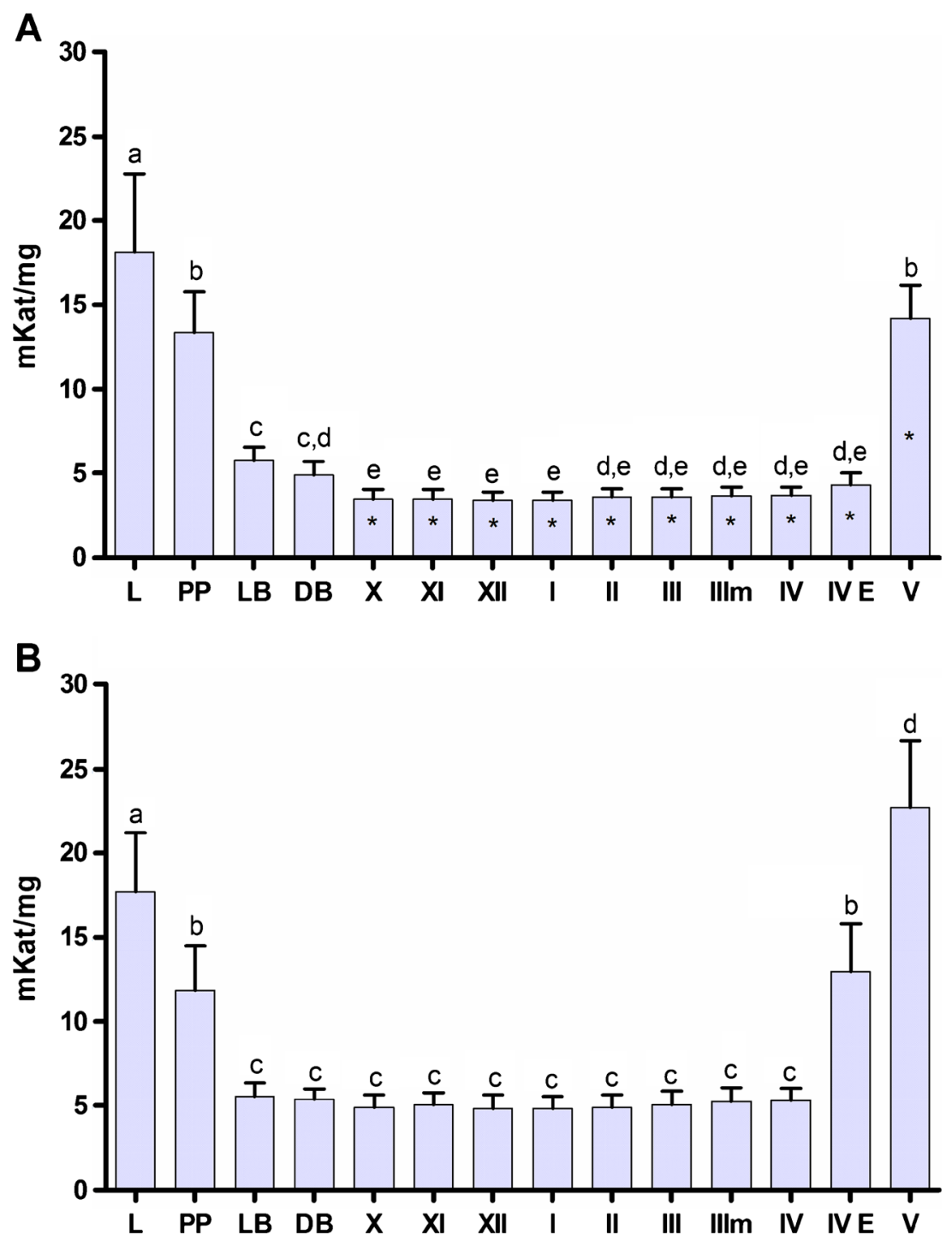

Figure 4. Catalase activity of Osmia bicornis female (A) and male (B). For explanation, see Fig. 1.

for subsequent developmental stages (JovanovicGalovic et al. 2004). It has been suggested that antioxidant enzymes have overlapping functions to promote stable development and homeostasis during diapause and metamorphosis (Stanic et al. 2004). The above observations explain the activity of antioxidant enzymes and non-enzymatic antioxidants in all examined stages of O. bicornis ontogenesis (Figs. 1, 2, 3, 4, 5, and 6). A similar pattern of changes in the analyzed parameters was noted during the insect life cycle. The following phases can be identified: 1) high levels of the analyzed parameters in larvae, 2) reduced levels of the analyzed parameters during metamorphosis (excluding glutathione), 3) nearly stable levels of the analyzed parameters in overwintering insects, 4) a significant increase in the values of the analyzed parameters in bees emerging from cocoons (excluding TAS whose values decreased).

We investigated the full extract of an insect's body. We are aware that the results may differ in some ways from those obtained for individual tissue, but this approach allows you to know a 


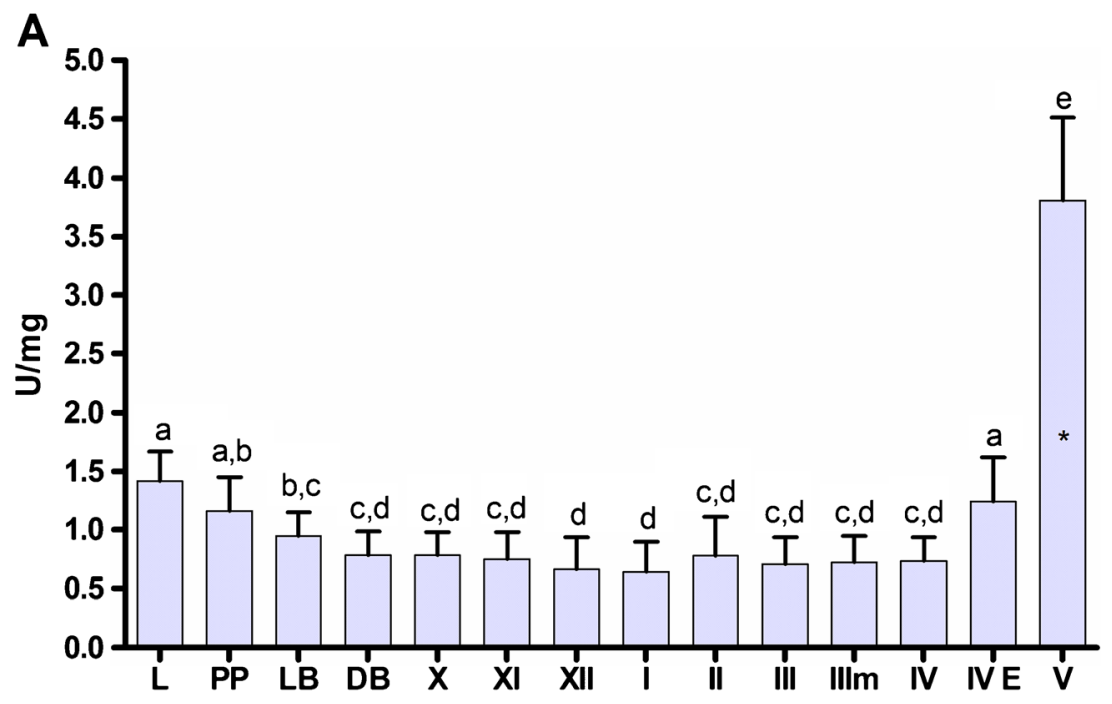

B

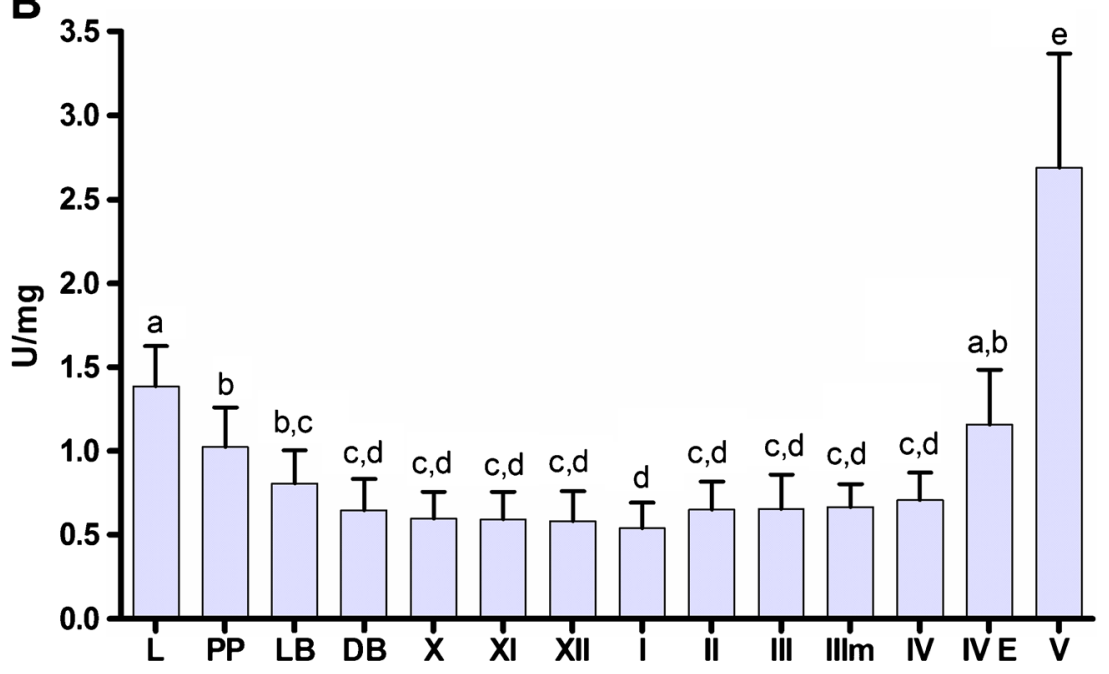

Figure 5. Peroxidase activity of Osmia bicornis female (A) and male (B). For explanation, see Fig. 1.

general antioxidant status in the whole organism for a particular developmental stage of insect.

The highest activity of antioxidant enzymes was observed in mature, active individuals of O. bicornis. High enzyme activity levels in the imago could be attributed to intensified mitochondrial activity due to high energy demands at this stage, especially during flight. Flight generates spectacular rates of metabolism, and the flight muscles are exposed to high levels of ROS (Williams et al. 2008). Similarly to active bees, larvae were characterized by very high levels of antioxidative enzyme activity. Both active bees and larvae are feeding stages, which suggests that food affects the activity of antioxidant enzymes. The role of antioxidant enzymes in defense against food allelochemicals was confirmed by numerous authors (Perić-Mataruga et al. 1997; Barbehenn et al. 2001; Barbehenn 2003; Krishnan and Kodrik 2006; Krishnan et al. 2007; Buyukguzel and Kalender 2009; Żaak et al. 2012). Krishnan and Kodrik (2006) demonstrated that antioxidant enzymes are upregulated to protect the body against endogenous and exogenous 

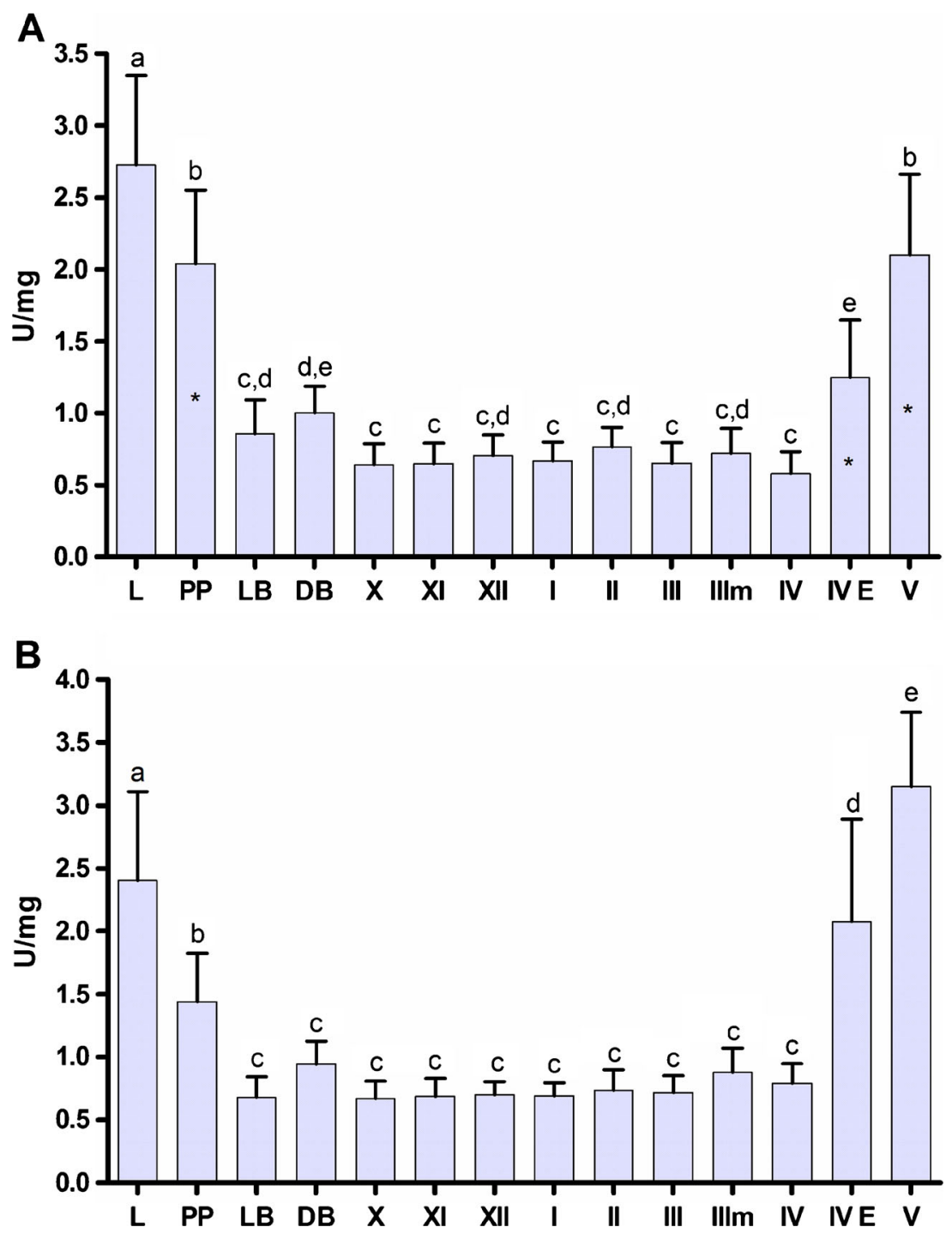

Figure 6. The activity of glutathione S-transferase of Osmia bicornis female (A) and male (B). For explanation, see Fig. 1.

oxidative radicals generated by the ingested prooxidant allelochemicals. The upregulation mechanism was described by Perić-Mataruga et al. (1997), who also observed that antioxidant enzymes may be inhibited in some cases. The above suggestion was confirmed by significantly lower enzyme activity levels in non-feeding stages. Beginning in the prepupal stage, the activity of antioxidant enzymes was lowered and practically stabilized in fully transformed, overwintering individuals. Contrary to expectations, the activity of antioxidant enzymes decreased during metamorphosis. We are unable to fully account for this phenomenon. The metamorphosis is a period of intensive reconstruction of tissues and organs. Antioxidant enzymes play a significant role in scavenging ROS generated during pupal-adult metamorphosis, which induces programmed cell death and tissue remodeling (Noh et al. 2010). According to Jovanovic-Galovic et al. (2004), various components may be involved in antioxidant protection to preserve homeostasis in different stages of development. This observation is partially validated by the results of this study. Glutathione levels rose during metamorphosis, but 
the observed increase cannot be expected to fully compensate for the drop in the activity of antioxidant enzymes. Glutathione is considered to be the most important low molecular weight antioxidant that plays a key role in ROS removal (Krishnan et al. 2009). Unlike in O. bicornis, glutathione concentrations decreased by up to $60 \%$ during metamorphosis in other insects (Allen and Sohal 1986).

O. bicornis overwinters in the imago stage, during which the metabolic rate slows down in response to lower temperature and the production of endogenous ROS decreases. Overwintering individuals remain in cocoons hidden in nesting material and are less exposed to exogenous stressors. The above could explain the relatively stable, but clearly lower activity levels of antioxidant enzymes and higher levels of glutathione, which is less intensely used. GSH levels increased in overwintering $O$. bicornis, but this is not a rule for all insects. GSH levels decreased in diapausing Ostrinia nubilalis (Jovanovic-Galovic et al. 2004). TAS was the only parameter whose value was lower in overwintering mason bees than in active individuals. This unexplained phenomenon could be controlled by a peculiar biological clock. The above assumption was validated by a study of $O$. bicornis where individuals were kept at constant low temperature and where TAS values decreased in response to an artificially extended diapause (Dmochowska et al. 2012). Further research is required to explain this highly interesting phenomenon.

As expected, the observed changes in the analyzed elements of the antioxidant system in developing O. bicornis males and females were not significant. Most differences were reported in the activity of catalase, which was lower in overwintering imagines and active females than in males. Interesting differences between genders were observed only in GST levels. In pre-pupae, higher GST levels were noted in females, whereas in emerged and active bees, GST activity levels were higher in males. GST levels also differed between genders in another solitary bee species-Megachile rotundata (Fröhlich et al. 1989). The drop in TAS values, which began earlier in male than female imagines, was yet another sex-related difference. In active males, TAS levels were nearly $50 \%$ lower than in newly emerged insects, whereas in the latter, TAS values were approximately $40 \%$ lower in comparison with overwintering individuals. In effect, TAS levels in active males were three times lower than in overwintering imagines. The observed differences seem to be related to the length of the insects' life cycle, because males emerge earlier than females and live for a shorter duration outside the cocoon (Wilkaniec 1991).

A comparison of antioxidant systems in $O$. bicornis and the honeybee $A$. mellifera produced highly interesting results. It is believed that social insects have weaker antioxidant and detoxification systems than solitary insects (Oakeshott et al. 2010). This hypothesis has been put forward based on the results of genetic studies into insects that are quite distant from the honeybee, including Drosophila melanogaster, Anopheles gambiae and Nasonia vitripennis. A comparison of the honeybee and the red mason bee seems to be more appropriate for verifying this hypothesis. The results of this study and other authors' findings indicate that TAS levels were higher during the development of mason bees than honeybees (Lipiński et al. 2008; Farjan et al. 2012). TAS values did not change in a developing honeybee brood (Farjan et al. 2012), which could be attributed to relatively stable conditions inside the beehive during the relatively short period of brood development. Mason bees develop at a much slower rate and at much less stable conditions. Adult mason bees were characterized by the highest GSH content during development, whereas lower GSH levels were noted in emerged workers of $A$. mellifera than in their brood. In honeybees, SOD activity was lower in the imago stage than in earlier stages of development (Farjan et al. 2012). The reverse was observed in O. bicornis, where SOD activity was 2.5-fold higher in active bees than in feeding larvae. In solitary bees, peroxidase activity was more than 40-fold higher than in honeybee communities (Lipiński and Żółtowska 2005; Saltykova et al. 2007; Lipiński et al. 2008; Farjan et al. 2012), which could be attributed to the different tasks and roles played by females in both species. Honeybee workers remain in the hive for three weeks, where they perform various tasks. Conversely, mason bees become active pollen pickers immediately after leaving their cocoons, and they are exposed to a host of new, not always positive, environmental factors. Reproduction also starts immediately in 
mason bees, which is not the case in honeybee workers. Those and other factors support the production of free radicals in mature mason bees. Above all, free radicals are produced in response to an increase in the metabolic rate, for example during intense flight. Consequently, the antioxidant system has to reach a high level of efficiency over a very short period of time to minimize the harmful effects of oxidation stress. It can be assumed that such dramatic changes in the efficiency of the antioxidant system are not required in honeybee workers, which have a highly structured system of roles and life functions.

The results of this study confirm the hypothesis formulated by Oakeshott et al. (2010) that at the molecular level, the antioxidant systems of solitary insects are more efficient than those of insects living in communities. A comparison of parameters describing $O$. bicornis and A. mellifera validates the above conclusion (Lipiński and Żółtowska 2005; Saltykova et al. 2007; Lipiński et al. 2008; Farjan et al. 2012).

\section{ACKNOWLEDGMENTS}

This work was partially supported by Grant DEC2012/07/N/NZ9/01298 from National Science Centre, Poland. Kamila Dmochowska-Ślęzak was supported by a scholarship program for PhD students: "DrINNO 3 building of social potential of highly qualified specialists in the Warmia and Mazury".

\section{OPEN ACCESS}

This article is distributed under the terms of the Creative Commons Attribution License which permits any use, distribution, and reproduction in any medium, provided the original author(s) and the source are credited.

Variations du système de défense antioxydant au cours du développement de l'abeille solitaire Osmia bicornis

antioxydant / insecte pollinisateur / métabolisme / développement / enzymes

Variabilität der antioxidativen Verteidigung während der Entwicklung der Solitärbiene Osmia bicornis

Antioxidantien / Bestäuberinsekten / Insektenmetabolismus / Entwicklung / Enzyme

\section{REFERENCES}

Aebi, H. (1984) Catalase in vitro. Methods Enzymol. 105, $121-126$

Aitken, A., Learmonth, M. (1996) Protein determination by UV absorption. In: Walker, J.M. (ed.) The Protein Protocols Handbook, Part I, p. 967. Humana Press Inc., Totowa

Allen, R.G., Sohal, R.S. (1986) Role of glutathione in aging and development of insects. In: Collatz, K.G., Sohal, R.S. (eds.) Insect Aging: Strategies and Mechanisms, pp. 168-181. Springer, Heidelberg

Alston, D.G., Tepedino, V.J., Bradley, B.A., Toler, T.R., Griswold, T.L., Messinger, S.M. (2007) Effects of the insecticide phosmet on solitary bee foraging and nesting in orchards of Capitol Reef National Park, Utah. Environ. Entomol. 36, 811-816

Barbehenn, R.V. (2003) Antioxidants in grasshoppers: higher levels defend the midgut tissues of a polyphagous species than a graminovorous species. J. Chem. Ecol. 29, 683-702

Barbehenn, R.V., Bumgarnenr, S.L., Roosen, E.F., Martin, M.M. (2001) Antioxidant defenses in caterpillars: role of the ascorbate-recycling system in the midgut lumen. J. Insect Physiol. 47, 349-357

Bartosz, G. (2003) Druga twarz tlenu. Wydawnictwo Naukowe PWN

Biliński, M., Teper, D. (2004) Rearing and utilization of the red mason bee - Osmia rufa L. (Hymenoptera, Megachilidae) for orchard pollination. J. Apic. Sci. 48, 69-74

Buyukguzel, E., Kalender, Y. (2009) Exposure to streptomycin alters oxidative and antioxidative response in larval midgut tissues of Galleria mellonella. Pestic. Biochem. Physiol. 94, 112-118

Candy, D.J., Becker, A., Wegener, B. (1997) Coordination and integration of metabolism in insect flight. Comp. Biochem. Physiol. B 117, 497-512

Chance, B., Maehly, A.C. (1955) Assay of catalases and peroxidases. In: Colowick, S.P., Kaplan, N. (eds.) Methods in Enzymology, Vol. 2, pp. 764-775. Academic Press, Inc, New York

Chien, C., Motoyama, N., Dauterman, W.C. (1995) Separation of multiple forms of acidic glutathione Stransferase isozymes in a susceptible and a resistant strain of house fly, Musca domestica (L.). Arch. Insect Biochem. Physiol. 28, 397-406

Colinet, D., Cazes, D., Belghazi, M., Gatti, J.L., Poirie, M. (2011) Extracellular superoxide dismutase in insects: characterization, function, and interspecific variation in parasitoid wasp venom. J. Biol. Chem. 286, 4011040121

Colven, R.M., Pinnell, S.R. (1996) Topical vitamin C in aging. Clin. Dermatol. 14, 227-234

Corona, M., Robinson, G.E. (2006) Genes of the antioxidant system of the honey bee: annotation and phylogeny. Insect Mol. Biol. 15, 687-701 
Després, L., David, J.P., Gallet, C. (2007) The evolutionary ecology of insect resistance to plant chemicals. Trends Ecol. Evol. 22 , 288-307

Dietemann, V., Pflugfelder, J., Anderson, D., Charrière, J.D., Chejanovsky, N., et al. (2012) Varroa destructor: research avenues towards sustainable control. J. Apic. Res. 51, 125-132

Dmochowska, K., Giejdasz, K., Fliszkiewicz, M., Źóltowska, K. (2012) Changes in the antioxidant system of the red mason bees (Osmia rufa) induced by artificially elongated diapause. J. Apic. Sci. 56, 5-12

Ellman, G.L. (1959) Tissue sulfyhydryl groups. Arch. Biochem. Biophys. 82, 70-77

Farjan, M., Dmitryjuk, M., Lipiński, Z., Biernat-Łopieńska, E., Źóttowska, K. (2012) Supplementation of the honey bee diet with vitamin $C$ : The effect on the antioxidative system of Apis mellifera carnica brood at different stages. J. Apic. Res. 51, 263-270

Frazier, M., Mullin, C., Frazier, J., Ashcraft, S. (2008) What have pesticides got to do with it? Am. Bee J. 148, 521523

Fröhlich, D.R., Burris, T.E., Brindley, W.A. (1989) Characterization of glutathion-S-transferase in a solitary bee, Megachile rotunda (Fab.) (Hymenoptera: Megachilidea) and inhibition by chalcones, flavones, quercetin and triphanediol. Comp. Biochem. Physiol. 94, 661-665

Giejdasz, K., Wilkaniec, Z. (2000) Bionomics and reproduction of the bee Osmia rufa L. Megachilidae. (in polish) Rocz. Nauk. Zoot. 9, 57-60

Giejdasz, K., Wilkaniec, Z. (2002) Individual development of the red mason bee (Osmia rufa L., Megachilidae) under natural and laboratory conditions. J. Apic. Sci. 46, 51-57

Hayaoka, T., Dauterman, W.C. (1982) Induction of glutathione S-transferase by phenobarbital and pesticides in various house fly strains and its effect on toxicity. Pestic. Biochem. Physiol. 17, 113-119

Henry, M., Béguin, M., Requier, F., Rollin, O., Odoux, J.F., Aupinel, P., Aptel, J., Tchamitchian, S., Decourtye, A. (2012) A common pesticide decreases foraging success and survival in honey bees. Science 336, 348-350. doi:10.1126/science.1215039

Herbert Jr., E.W., Shimanuki, H. (1978) Chemical composition and nutritive value of bee-collected and beestored pollen. Apidologie 9, 33-40

Jovanovic-Galovic, A., Blagojevic, D., Grubor-Lajsic, G., Worland, R., Spasic, M.B. (2004) Role of antioxidant defense during different stages of preadult life cycle in European corn borer (Ostrinia nubilalis, Hübn.): diapause and metamorphosis. Arch. Insect Biochem. Physiol. 55, 79-89

Klein, A.M., Bernard, E., Vaissière, B.E., Cane, J.H., Steffan-Dewenter, I., Cunningham, S.A., Kremen, C., Tscharntke, T. (2007) Importance of pollinators in changing landscapes for world crops. Proc. R. Soc. Lond. B Biol. Sci. 274, 303-313

Krishnan, N., Kodrik, D. (2006) Antioxidant enzymes in Spodoptera littoralis (Boisduval): are they enhanced to protect gut tissues during oxidative stress? J. Insect Physiol. 52, 11-20

Krishnan, N., Kodrik, D., Turanli, F., Sehnal, F. (2007) Stage specific distribution of oxidative radicals and antioxidant enzymes in the midgut of Leptinotarsa decemlineata. J. Insect Physiol. 53, 67-74

Krishnan, N., Kodrik, D., Kłudkiewicz, B., Sehnal, F. (2009) Glutathione-ascorbic acid redox cycle and thioredoxin reductase activity in the digestive tract of Leptinotarsa decemlineata (Say). Insect Biochem. Mol. Biol. 39, 180-188

Lipiński, Z., Żółtowska, K. (2005) Preliminary evidence associating oxidative stress in honey bee drone brood with Varroa destructor. J. Apic. Res. 44, 126-128

Lipiński, Z., Farjan, M., Żółtowska, K., Polaczek, B. (2008) Effects of dietary transgenic Bt maize pollen on hive worker honeybees. Pol. J. Environ. Stud. 17, 957-961

Noh, M.Y., Jo, Y.H., Park, C.H., Lee, E.S., Lee, H.J., Kim, I., Lee, Y.S., Seo, S.J., Bang, I.S., Kim, S., Han, Y.S. (2010) Cloning and induction patterns of $\mathrm{Cu} / \mathrm{Zn}$ superoxide dismutase in responses to immune elicitors and nucleopolyhedrovirus in the beet armyworm Spodoptera exigua. Entomol. Res. 40, 336-342

Oakeshott, J.G., Johnson, R.M., Berenbaum, M.R., Ranson, H., Cristino, A.S., Claudianos, C. (2010) Metabolic enzymes associated with xenobiotic and chemosensory responses in Nasonia vitripennis . Insect Mol. Biol. 19, 147-163

Perić-Mataruga, V., Blagojevic, D., Spasic, M.B., Ivanovic, J., Jankovic-Hladni, M. (1997) Effect of the host plant on the antioxidative defence in the midgut of Lymantria dispar L. Caterpillars of different population origins. J. Insect Physiol. 43, 101-106

Potts, S.G., Biesmeijer, J.C., Kremen, C., Neumann, P., Schweiger, O., Kunin, W.E. (2010) Global pollinator declines: trends, impacts and drivers. Trends Ecol. Evol. 25, 345-353

Radmacher, S., Strohm, E. (2011) Effects of constant and fluctuating temperatures on the development of the solitary bee Osmia bicornis (Hymenoptera, Megachilidae). Apidologie 42, 711-720

Re, R., Pellegrini, N., Proteggen, A., Pannala, A., Yang, M., Rice-Evans, C. (1999) Antioxidant activity applying and improved ABTS radical cation decolorization assay. Free Radic. Biol. Med. 26, 1231-1237

Rice-Evans, C.A., Diplock, A.T., Symons, M.C.R. (1991) Techniques in Free Radical Research. Elsevier, London

Saltykova, E.S., Benkovskaya, G.V., Nikolenko, A.G. (2007) Intraspecies differences in mechanisms of formation of protective processes in the honeybee Apis mellifera. J. Evol. Biochem. Physiol. 43, 191-197

Stanic, B., Jovanovic-Galovic, A., Blagojevic, D., Gruborlajsic, G., Worland, R., Spasic, M.B. (2004) Cold hardiness in Ostrinia nubilalis (Lepidoptera: Pyralidae): Glycerol content, hexose monophosphate shunt activity and antioxidative defense system. Eur. J. Entomol. 101, 459-466 
Teper, D., Biliński, M. (2009) Red mason bee (Osmia rufa L.) as a pollinatior of rape plantation. J. Apic. Sci. 53, 115-120

Tilman, D., Fargione, J., Wolff, B., D’Antonio, C., Dobson, A., Howarth, R., Schindler, D., Schlesinger, W.H., Simberloff, D., Swackhamer, D. (2001) Forecasting agriculturally driven global environmental change. Science 292, 281-284

Whitehorn, P.R., O'Connor, S., Wackers, F.L., Goulson, D. (2012) Neonicotinoid pesticide reduces bumble bee colony growth and queen production. Science 336, 351-352

Wilkaniec, Z. (1991) Możliwość zastosowania Osmia rufa L. (Apoidea, Magachilidae) w zapylaniu niektórych roślin uprawnych. Rocz. AR Pozn. 229, 173-179

Wilkaniec, Z., Giejdasz, K., Prószyński, G. (2004) Effect of pollination of onion seeds under isolation by the red mason bee (Osmia rufa L.) (Apoidea, Megachilidae) on the setting and quality of obtained seeds. J. Apic. Sci. 48, 35-41

Williams, J.B., Roberts, S.P., Elekonich, M.M. (2008) Age and natural metabolically intensive behavior affect oxidative stress and antioxidant mechanisms. Exp. Gerontol. 43, 538-549

Wójtowski, F., Wilkaniec, Z. (1978) Rearing and utilization of solitary bees settled in nest traps (in Polish). Instr. Wdroż. AR Poznań 1-10

Yu, S.J. (1996) Insect glutathione S-transferases. Zool. Stud. 35, 9-19

Żaak, M., Migula, P., Stygar, D., Dolezych, B., Michalczyk, K. (2012) Within and between seasonal changes of detoxifying capabilities of Cameraria ohridella (Lepidoptera: Gracillariidae) larvae. C. R. Biol. 335, 645-656 